\title{
Cloning and Identification of Human Sca as a Novel Inhibitor of Osteoclast Formation and Bone Resorption
}

\author{
Sun Jin Choi, ${ }^{\star}$ Rowena D. Devlin, ${ }^{\star}$ Cheikh Menaa, ${ }^{\star}$ Hoyeon Chung, ${ }^{\star}$ G. David Roodman, ${ }^{\star \ddagger}$ and Sakamuri V. Reddy \\ ${ }^{*}$ Department of Medicine/Hematology, University of Texas Health Science Center, San Antonio, Texas 78284; and ${ }^{\ddagger}$ the Audie Murphy \\ Veterans Administration Hospital, San Antonio, Texas 78284
}

\begin{abstract}
Increased osteoclast activity is responsible for the enhanced bone destruction in postmenopausal osteoporosis, Paget's disease, bone metastasis, and hypercalcemia of malignancy. However, the number of known inhibitory factors that block osteoclast formation and bone resorption are limited. Therefore, we used an expression-cloning approach to identify novel factors produced by osteoclasts that inhibit osteoclast activity. A candidate clone was identified and isolated from a human osteoclast-like multinucleated cell (MNC) cDNA library, named osteoclast inhibitory peptide-1 (OIP-1), and the cDNA sequence was determined. This sequence matched that of the recently identified human stem cell antigen, was structurally similar to the mouse Ly-6 gene family, and the sequence predicted it was a glycosyl phosphatidyl inositol (GPI)-anchored protein that had a cleavable $\mathrm{COOH}$-terminal peptide. Western blot analysis of conditioned media from 293 cells transfected with the OIP-1 cDNA clone confirmed that OIP-1 was released into the media as a membranebound GPI-linked protein. Interestingly, both recombinant OIP-1 expressed in Escherichia coli (which does not have GPI linker) and OIP-1 expressed by mammalian cells significantly reduced osteoclast-like MNC formation induced by 1,25-dihydroxyvitamin $\mathrm{D}_{3}$ or PTH-related protein in mouse and human bone marrow cultures, and inhibited ${ }^{45} \mathrm{Ca}$ release from prelabeled bone in fetal rat organ cultures. In contrast, recombinant OIP-1 did not inhibit the growth of a variety of other cell types. These data indicate that OIP-1 is a novel, specific inhibitor of osteoclast formation and bone resorption. (J. Clin. Invest. 1998. 102:1360-1368.) Key words: osteoclast $\bullet$ bone marrow cultures $\bullet$ hSca $\bullet$ expression cloning $\bullet$ inhibitors
\end{abstract}

\section{Introduction}

Osteoclasts are the primary cells responsible for bone resorption. Recent evidence has suggested that the osteoclast is a secretory cell that produces factors that can stimulate or in-

Address correspondence to Dr. Sakamuri V. Reddy, Medicine/Hematology, University of Texas Health Science Center, 7703 Floyd Curl Drive, San Antonio, TX 78284. Phone: 210-567-4832; FAX: 210567-1956.

Received for publication 29 December 1997 and accepted in revised form 29 July 1998.

J. Clin. Invest.

(C) The American Society for Clinical Investigation, Inc. 0021-9738/98/10/1360/09 \$2.00

Volume 102, Number 7, October 1998, 1360-1368

http://www.jci.org hibit its own formation/activity (1). To identify secretory factors produced by osteoclasts that regulate osteoclast formation and/or activity, we used an expression-cloning approach with a cDNA library derived from highly purified human osteoclastlike cells formed in vitro (2). We have recently identified a new osteoclast stimulatory factor $(\mathrm{OSF})^{1}$ by this approach, which can stimulate formation of human and mouse osteoclast-like cells in vitro and bone resorption in bone organ cultures (3).

Importantly, in addition to stimulatory factors of osteoclast activity, osteoclasts also produce factors that inhibit osteoclast activity. Oursler et al. (4) reported that TGF- $\beta$ is produced by osteoclasts and is then activated in the bone microenvironment. Pfeilschifter and Mundy (5) had previously demonstrated that latent TGF- $\beta$ was activated by osteoclasts during bone adsorption, and Chenu et al. (6) have shown that TGF- $\beta$ inhibits all stages of osteoclast formation.

Using this approach, we report the identification and initial characterization of a novel glycosyl phosphatidyl inositol (GPI)-linked osteoclast inhibitory factor (OIP-1), which blocks osteoclast formation in both long-term human and murine bone marrow cultures and ${ }^{45} \mathrm{Ca}$ release from fetal rat long bones stimulated by 1,25 -dihydroxyvitamin $\mathrm{D}_{3}\left(1,25(\mathrm{OH})_{2} \mathrm{D}_{3}\right)$ or PTH-related protein (PTHrP).

GPI-linked proteins are membrane-bound proteins that can be shed from the cell surface in membrane-bound vesicles or cleaved and released by the action of phospholipase $\mathrm{C}$ (PLC), PLD, or other proteolytic enzymes. These proteins have been reported to act as cell activators, cell communicators, and signaling molecules in hematopoietic cells (7). Our data suggest that OIP-1 is a GPI-linked protein that is released from the cell surface as a membrane-bound protein and negatively regulates osteoclast formation/activity.

\section{Methods}

Material. DNA transfection kits were obtained from Stratagene (La Jolla, CA), and cDNA synthesis kits were purchased from Pharmacia Biotech Inc. (Piscataway, NJ). PCR kits were obtained from PerkinElmer Cetus Corporation (Foster City, CA). All restriction enzymes used were from New England Biolabs Inc. (Beverly, MA) and GIBCO BRL (Gaithersburg, MD), and chemicals were from Sigma Chemical Co. (St. Louis, MO). The $23 \mathrm{c} 6$ monoclonal antibody was generously provided by Dr. Michael Horton (The Rayne Institute, London, UK).

Screening the mammalian expression library. A human osteoclastlike cell cDNA expression library was prepared as described previ-

1. Abbreviations used in this paper: GPI, glycosyl phosphatidyl inositol; OIP-1, osteoclast inhibitory peptide-1; OSF, osteoclast stimulatory factor; PTHrP, parathyroid hormone-related protein; RIG-E, retinoic acid induced gene expression; Sca, stem cell antigen; TRAP $(+)$ MNCs, tartrate-resistant acid phosphatase positive multinucleated cells. 
ously (2), and pools containing 2,000 independent clones each were screened. Briefly, column-purified plasmid DNA (10 $\mu \mathrm{g}$; Qiagen, Inc., Chatsworth, CA) of each pool was transiently transfected into 293 cells $\left(4 \times 10^{5}\right)$ grown in individual 35 -mm wells, using the calcium phosphate method with a kit from Stratagene according to the manufacturer's protocol. $12 \mathrm{~h}$ after the start of the DNA transfection process, the cells were washed with $3 \mathrm{ml}$ of serum-free DME and fed with $1.5 \mathrm{ml}$ of the same medium. Conditioned medium from each pool was collected after $48 \mathrm{~h}$ and tested at different concentrations $(0.1-10 \%$, $\mathrm{vol} / \mathrm{vol}$ ) for its capacity to inhibit tartrate-resistant acid phosphatase positive (TRAP $(+))$ osteoclast-like multinucleated cell (MNC) formation in mouse bone marrow cultures stimulated with $10^{-9} \mathrm{M}$ $1,25(\mathrm{OH})_{2} \mathrm{D}_{3}$. Pools that significantly and reproducibly inhibited TRAP(+) MNC formation in murine marrow cultures were then tested for their capacity to inhibit osteoclast-like MNC formation in human bone marrow cultures by counting the number of $23 \mathrm{c} 6$ antibody-reactive MNCs formed, as described below. Pools that contained inhibitory activity were progressively subfractionated until they contained only one cDNA clone. This cDNA clone was then sequenced by standard techniques, and the sequence was compared with the DNA database present in GenBank.

Murine bone marrow cultures. Bone marrow was collected aseptically from BALB/c mice by flushing the tibiae with $1 \mathrm{ml}$ of $\alpha$-MEM using a tuberculin syringe fitted with a 27.5 gauge needle. The cells were washed twice and resuspended in $\alpha$-MEM- $10 \%$ FCS. The marrow cell suspension was incubated in sterile $10-\mathrm{cm}$ plastic tissue culture dishes for $2 \mathrm{~h}$. The nonadherent cells were collected and cultured in quadruplicate for $6 \mathrm{~d}$ in 48 -well plates at a density of $1.0 \times 10^{6}$ cells/ well in $\alpha$-MEM- $10 \%$ FCS supplemented with $10^{-9} \mathrm{M} 1,25(\mathrm{OH})_{2} \mathrm{D}_{3}$ as described by Takahashi et al. (8). The cultures were fixed with 4.5 $\mathrm{mM}$ citric acid, $2.25 \mathrm{mM}$ sodium citrate, $3 \mathrm{mM}$ sodium chloride, $3 \%$ formaldehyde, and acetone, and were washed twice in distilled water. The cultures were then stained for TRAP activity using an acid phosphatase staining kit (Sigma Chemical Co.). The TRAP(+) MNCs containing three or more nuclei were counted.

Human bone marrow MNC cultures. Long-term human marrow cultures were performed as described previously (9). In brief, human bone marrow nonadherent mononuclear cells from normal volunteers were cultured at $10^{6}$ cells $/ \mathrm{ml}$ in $\alpha$-MEM- $20 \%$ horse serum with or without $10^{-9} \mathrm{M} 1,25(\mathrm{OH})_{2} \mathrm{D}_{3}$ and with varying concentrations of OIP-1-conditioned media. Half of the culture medium was changed weekly. After $3 \mathrm{wk}$, the cultures were harvested and stained with the $23 \mathrm{c} 6 \mathrm{mAb}$, which identifies the osteoclast vitronectin receptor.

Effects of OIP-1-conditioned media on bone resorption in fetal rat organ cultures. Timed pregnant rats were injected with $250 \mu \mathrm{Ci}$ of ${ }^{45} \mathrm{Ca}$ at day 18 of gestation, and $1 \mathrm{~d}$ later the rats were sacrificed by cervical dislocation and the embryos removed. The explanted radii and ulnae were cultured on circles of membrane filter, mixed ester, $0.45 \mu \mathrm{m}$ (Markson LabSales Inc., Hillsboro, OR) on stainless steel grids in $0.5 \mathrm{ml}$ of BGJ medium (Sigma Chemical Co.) supplemented with $1 \mathrm{mg} / \mathrm{ml}$ BSA (Sigma Chemical Co.) and penicillin-streptomycin $\left(50 \mathrm{U} / \mathrm{ml}\right.$ and $50 \mathrm{mg} / \mathrm{ml}$ ), in a controlled atmosphere of $5 \% \mathrm{CO}_{2}$ in air at $37^{\circ} \mathrm{C}$, as described by Raisz and Niemann (10). Bones were incubated for $24 \mathrm{~h}$ in control medium to allow for the removal of the exchangeable ${ }^{45} \mathrm{Ca}$ and then transferred to fresh medium. Bone resorption was stimulated with $10^{-9} \mathrm{M} 1,25(\mathrm{OH})_{2} \mathrm{D}_{3}$ or $20 \mathrm{ng} / \mathrm{ml} \mathrm{PTHrP} \mathrm{in}$ the presence or absence of varying concentrations of OIP-1-conditioned media. Control and experimental media were then changed after $72 \mathrm{~h}$, and the bone explants were incubated for a total of $5 \mathrm{~d}$. Bone-resorbing activity was measured as percent of total ${ }^{45} \mathrm{Ca}$ released from the bone into the medium over $5 \mathrm{~d}$ of incubation. The organ culture assay reflects bone resorption due to osteoclast formation, as well as that by preexisting mature osteoclasts.

Northern blot analysis of the tissue distribution of OIP-1. The OIP-1 cDNA was digested with restriction endonuclease BamHI, separated by agarose gel electrophoresis, and recovered from the gel using a DEAE membrane (S\&S Co., Dassel, Germany) according to the manufacturer's protocol. $\alpha-\left[{ }^{32} \mathrm{P}\right] \mathrm{dCTP}$ radiolabeled OIP-1 cDNA probe with specific activity of greater than $2 \times 10^{9} \mathrm{cpm} / \mu \mathrm{g}$ DNA was prepared using a random priming kit (GIBCO BRL), and Northern blot analysis was done with a human Multiple Tissue Northern (MTN) blot (CLONTECH Laboratories Inc., Palo Alto, CA). The MTN filter was prehybridized for $3 \mathrm{~h}$ and then hybridized for $20 \mathrm{~h}$ with $10^{7}$ $\mathrm{cpm} / \mathrm{ml}$ aqueous hybridization fluid (6× SSPE, $1 \%$ SDS, $2 \times$ Denhardt's solution, $100 \mu \mathrm{g} / \mathrm{ml}$ salmon sperm DNA). The filters were washed with $0.2 \times$ SSC and $0.1 \%$ SDS, exposed in photographic cassettes, and visualized by autoradiography.

In situ hybridization. Human bone marrow cells were cultured in the presence of $1,25(\mathrm{OH})_{2} \mathrm{D}_{3}$ in LabTek chamber slides (Fisher Scientific, Houston, TX) as described. The cells were fixed in $4 \%$ paraformaldehyde and permeabilized by treatment with $0.2 \mathrm{M} \mathrm{HCl}$ for $5 \mathrm{~min}$ at room temperature. Nonspecific background hybridization was reduced by treatment with $0.25 \%$ ( $\mathrm{vol} / \mathrm{vol})$ acetic anhydride in $0.1 \mathrm{M}$ triethanolamine- $\mathrm{HCl}, \mathrm{pH} 8.0$, for $5 \mathrm{~min}$. The slides were washed in RNAse-free water and prehybridized for $1 \mathrm{~h}$ at $42^{\circ} \mathrm{C}$ in a solution containing $50 \%$ formamide, $5 \times$ Denhardt's solution, $5 \times$ SSC, $50 \mathrm{mM}$ sodium phosphate, $\mathrm{pH} 6.5,250 \mu \mathrm{g} / \mathrm{ml}$ sheared salmon sperm DNA, 250 $\mu \mathrm{g} / \mathrm{ml}$ yeast tRNA, and $0.1 \%$ SDS. Hybridization was carried out in 50 $\mu \mathrm{l}$ of the same buffer containing ${ }^{35} \mathrm{~S}$-labeled antisense or sense oligomers to OIP- $1 \mathrm{mRNA}\left(10^{6} \mathrm{cpm} / \mathrm{ml}\right)$ at $42^{\circ} \mathrm{C}$ for $24 \mathrm{~h}$. The slides were washed at $37^{\circ} \mathrm{C}$ in $2 \times \mathrm{SSC}$ to remove unbound probe. The slides were then washed once for $30 \mathrm{~min}$ in $50 \%$ formamide $/ 2 \times \mathrm{SSC} / 2-\mathrm{ME}$ at $42^{\circ} \mathrm{C}$, twice for $10 \mathrm{~min}$ in $2 \times \mathrm{SSC}-0.1 \%$ SDS at room temperature, and once for $10 \mathrm{~min}$ in $0.1 \times \mathrm{SSC}-0.1 \%$ SDS at room temperature. The slides were air dried, and autoradiography was performed using nuclear tracking emulsion (NTB2; Eastman Kodak Co., Rochester, NY) and developing reagents as previously described $(11,12)$. The slides were counterstained with $0.5 \%(\mathrm{vol} / \mathrm{vol})$ methyl green. Cells hybridized with a sense oligomer served as controls for these experiments.

Expression of recombinant OIP-1 protein in Escherichia coli. From the pcDNA1 mammalian expression clone, the coding region for the OIP-1 cDNA was amplified by PCR with two primers, GCCATATGAAGATCTTCTTGCCAG and GAGGATCCGGTCAGGGGCCAAACCGC, and subcloned into the PET/14b vector between the NdeI and BamHI sites. This vector adds an $\mathrm{NH}_{2}$-terminal His tag fusion at the NdeI site, which can be cleaved by thrombin. After transformation, the plasmid construct (14/b OIP-1) was verified by restriction mapping and sequence analysis, and retransformed into $E$. coli (BL-21). $50 \mathrm{ml}$ of LB medium was inoculated with a single colony of bacteria E. coli (BL21) 14/b OIP-1 and incubated for $4 \mathrm{~h}$ as a seed culture. 2 liters of culture media was then inoculated with $1 \%$ (vol/ $\mathrm{vol}$ ) of the seed culture and incubated for $2 \mathrm{~h}$ more at $37^{\circ} \mathrm{C}$. Recombinant OIP-1 expression was induced with $1 \mathrm{mM}$ IPTG for $4 \mathrm{~h}$, and the cells were sedimented by centrifugation. The cell pellet was washed with $50 \mathrm{ml}$ of PBS and resuspended in $20 \mathrm{ml}$ of PBS in the presence of $1 \mathrm{mM}$ PMSF (Sigma Chemical Co.). After sonication on ice, the disrupted cells were sedimented at $12,000 \mathrm{~g}$ for $20 \mathrm{~min}$ at $4^{\circ} \mathrm{C}$. The pellet was resuspended in $20 \mathrm{ml}$ of $6 \mathrm{M}$ guanidine hydrochloride solution with $20 \mathrm{mM}$ sodium phosphate buffer, $\mathrm{pH} 7.5,0.5 \mathrm{M} \mathrm{NaCl}$, and 10 $\mathrm{mM}$ imidazole. After centrifugation (at 12,000 $\mathrm{g}$ ) for $20 \mathrm{~min}$, the supernatant was removed carefully and loaded onto a His-Bind Resin (Novagen Co., Cambridge, MA) according to the manufacturer's protocol. Recombinant OIP-1 fusion protein was eluted with an imidazole gradient (50-75 mM), and the eluate was dialyzed against milli Q water overnight. The precipitate was collected by centrifugation and washed with milli $\mathrm{Q}$ water three times and dissolved in $10 \mathrm{mM} \mathrm{HCl}$ with $20 \%$ glycerol. This purified recombinant OIP-1, which encompasses the entire open reading frame, was used to generate polyclonal OIP-1 antisera as described below after the $\mathrm{NH}_{2}$-terminal sequence of the recombinant protein was determined to confirm its identity and homogeneity.

Generation of polyclonal OIP-1 antisera. The recombinant OIP-1 protein was electrophoresed on a SDS-PAGE gel (15\%) and the $\sim 14$ kD OIP-1 band was removed and emulsified in PBS. A rabbit was immunized with $200 \mu \mathrm{g}$ of emulsified protein in a total volume of $0.2 \mathrm{ml}$. After $14 \mathrm{~d}$, the animal was hyperimmunized by injection of $200 \mu \mathrm{g} / 0.2$ 
$\mathrm{ml}$ of the same immunogen emulsified in PBS buffer. Three repeat challenges were performed every $14 \mathrm{~d}$. The specific reactivity of the OIP-1 antiserum was evaluated by its capacity to detect recombinant OIP-1 in a Western blot.

SDS-PAGE and Western immunoblotting. Conditioned media from 293 cells transiently transfected with the OIP-1 cDNA clone and cell lysates from these cells were collected. The conditioned media were further subjected to ultracentrifugation at 40,000 rpm using a Beckman SW50 rotor (Palo Alto, CA) for $4 \mathrm{~h}$ at $4^{\circ} \mathrm{C}$. The pellets and supernatant fractions obtained were collected separately. The samples were boiled in SDS sample buffer and loaded onto a $15 \%$ PAGE slab gel, which was stained with Coomassie blue. Electrophoretic transfer of protein from the polyacrylamide gel to nitrocellulose (S\&S) was performed using a Semi-Dry-Blotting Unit (Fisher Hamilton Inc., Madison, WI) at $20 \mathrm{~V}$ for $45 \mathrm{~min}$. After transfer, the nitrocellulose membrane was blocked with 5\% skim milk and then blotted with the OIP-1 polyclonal antibody at 1:3,000 dilution. The nitrocellulose membrane was then washed with TBST buffer and reacted with horseradish peroxidase-labeled sheep anti-rabbit IgG and visualized with the ECL system (Amersham Life Science Int., Buckinghamshire, UK) on Kodak X-AR5 film (Eastman Kodak Co.) according to the manufacturer's protocol.

Statistical analysis. Results are reported as the mean \pm SEM for five replicate samples and were compared by Student's $t$ test. Results were considered significantly different for $P<0.05$.

\section{Results}

Screening of the cDNA expression library. The cDNA expression library was initially screened by testing the effects of conditioned media from transfected 293 cells for their capacity to inhibit osteoclast-like MNC formation in mouse bone marrow cultures. Conditioned media (1-10\%) were added to mouse bone marrow cultures containing $10^{-9} \mathrm{M} 1,25(\mathrm{OH})_{2} \mathrm{D}_{3}$. The TRAP $(+)$ MNCs were counted and compared with the control cultures treated with conditioned media from 293 cells transfected with the empty pcDNA1 vector. Five pools that reproducibly inhibited MNC formation in murine marrow cultures treated with $10^{-9} \mathrm{M} 1,25(\mathrm{OH})_{2} \mathrm{D}_{3}$ were identified from the original 200 pools. The inhibitory pools were then screened by PCR for the presence of TGF- $\beta$ or $\gamma$-IFN, factors known to inhibit osteoclast formation. $\gamma$-IFN cDNA was detected in one of the pools (data not shown), which was not screened further.

Each of the remaining 4 inhibitory pools was divided into 12 subpools, containing 100-200 clones per subpool. The subpools were individually transfected into 293 cells, and the conditioned media were tested for their effects on $\operatorname{TRAP}(+)$ $\mathrm{MNC}$ formation stimulated with $1,25(\mathrm{OH})_{2} \mathrm{D}_{3}$ in mouse bone marrow cultures. One of the subpools, 105-3, inhibited MNC formation in three independent experiments and was further fractionated into individual clones in 96-well plates. Conditioned medium from the individual clones was then tested for its capacity to inhibit MNC formation as described above.

Effect of OIP-1-conditioned media on TRAP(+) MNC formation. The first inhibitory clone was designated OIP-1. In the mouse bone marrow cultures treated with $1,25(\mathrm{OH})_{2} \mathrm{D}_{3}$, conditioned media from 293 cells transfected with the OIP-1 cDNA clone (OIP-1 conditioned medium) decreased TRAP $(+)$ MNC formation by $\sim 60 \%$ at a concentration of $10 \%(\mathrm{vol} / \mathrm{vol})$ and inhibited TRAP $(+)$ MNC formation in a dose-dependent fashion at concentrations from 1-10\% (vol/vol) (Fig. $1 A$ ). In human bone marrow cultures, OIP-1-conditioned media decreased osteoclast-like MNC formation (23c6(+) MNC) in-
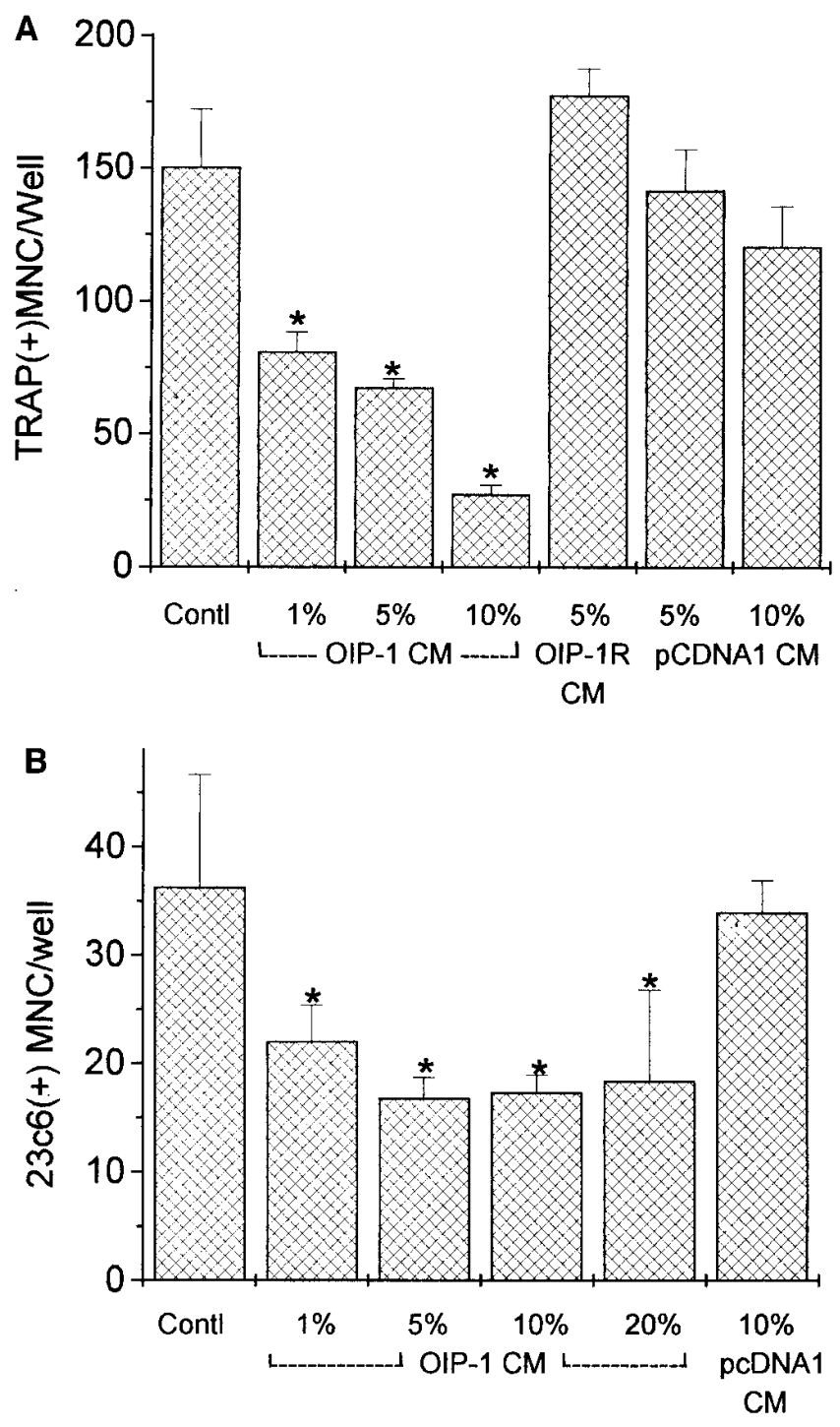

Figure 1. Effects of conditioned media from 293 cells transfected with the OIP-1 cDNA on mouse and human bone marrow osteoclastlike MNC formation. Varying concentrations ( $0-20 \% \mathrm{vol} / \mathrm{vol})$ of conditioned media $(C M)$ from 293 cells transfected with the OIP-1 cDNA, the OIP-1 cDNA in reverse orientation $(O I P-1 R)$, or the empty pcDNA1 vector were added to normal mouse bone marrow cultures $(A)$ or human marrow cultures $(B)$ stimulated with $10^{-9} \mathrm{M}$ $1,25(\mathrm{OH})_{2} \mathrm{D}_{3}$, as described in Methods. Results are presented as the number of TRAP $(+)$ MNCs (murine marrow) or the number of $23 \mathrm{c} 6$ antibody reactive MNCs/well (human marrow). Results represent the mean \pm SEM for four determinations from a typical experiment. Similar results were seen in five independent experiments. $* P<0.05$ compared with the control cultures treated with $1,25(\mathrm{OH})_{2} \mathrm{D}_{3}$ alone.

duced by $10^{-9} \mathrm{M} 1,25(\mathrm{OH})_{2} \mathrm{D}_{3} \sim 60 \%$, compared with the control cultures at the concentration of $5 \%$ ( vol/vol) (Fig. $1 \mathrm{~B}$ ). OIP-1-conditioned media also inhibited MNC formation $\sim 50 \%$ in murine and human marrow cultures treated with PTHrP (20 $\mathrm{ng} / \mathrm{ml}$ ) (data not shown).

Effects of OIP-1-conditioned media on bone resorption in fetal rat bone organ cultures. ${ }^{45} \mathrm{Ca}-$ labeled fetal rat long bones were stimulated with $10^{-9} \mathrm{M} 1,25(\mathrm{OH})_{2} \mathrm{D}_{3}$ and treated with 
varying concentrations of OIP-1-conditioned media. OIP-1conditioned media significantly inhibited ${ }^{45} \mathrm{Ca}$ release compared with conditioned media from 293 cells transfected with the empty pcDNA1 vector. OIP-1-conditioned media also inhibited PTHrP-stimulated bone resorption $(20 \mathrm{ng} / \mathrm{ml})$ in a dose-dependent manner and inhibited ${ }^{45} \mathrm{Ca}$ release $\sim 50 \%$ at a concentration of $32 \%$ ( $\mathrm{vol} / \mathrm{vol})$, compared with no inhibition by conditioned media from 293 cells transfected with the empty pcDNA1 vector only (Fig. 2).

Identification of OIP-1 clone as the cDNA for the human stem cell antigen ( $h S c a$ ) and human RIG-E. The OIP-1 cDNA was 1122 bp nucleotides in length. It encoded a 393 bp open reading frame, polyadenylation signal, and a poly(A) tail (Fig. 3). Comparison of the OIP-1 cDNA sequence with the other sequences in the GenBank database revealed that it was identical to the recently reported hSca $(13,14)$, also designated as retinoic acid-induced gene expression (RIG-E) (15). This gene (OIP-1/hSca/RIG-E) shares some homology with CD59 (16) and with the human epidermal growth factor receptor (14). OIP-1 also shares structural homology with the mouse Ly-6 gene family, which are cysteine-rich small peptides expressed in hematopoietic cells $(14,17)$. Analysis of the deduced amino acid sequence of the OIP- 1 cDNA predicted that it was a GPI-anchored cell surface protein that contained a 20 amino acid $\mathrm{NH}_{2}$-terminal cleavable signal peptide, a 79 amino acid extracellular peptide, and a 32 amino acid COOH-terminal GPI-linker peptide.

Tissue and cellular distribution of OIP-1 expression. Northern blot analysis of RNAs from multiple human tissues showed the highest expression of OIP-1 in liver and lower levels in heart, lung, pancreas, kidney, skeletal muscle, placenta, and brain (Fig. $4 A$ ). We also detected significant levels of OIP-1

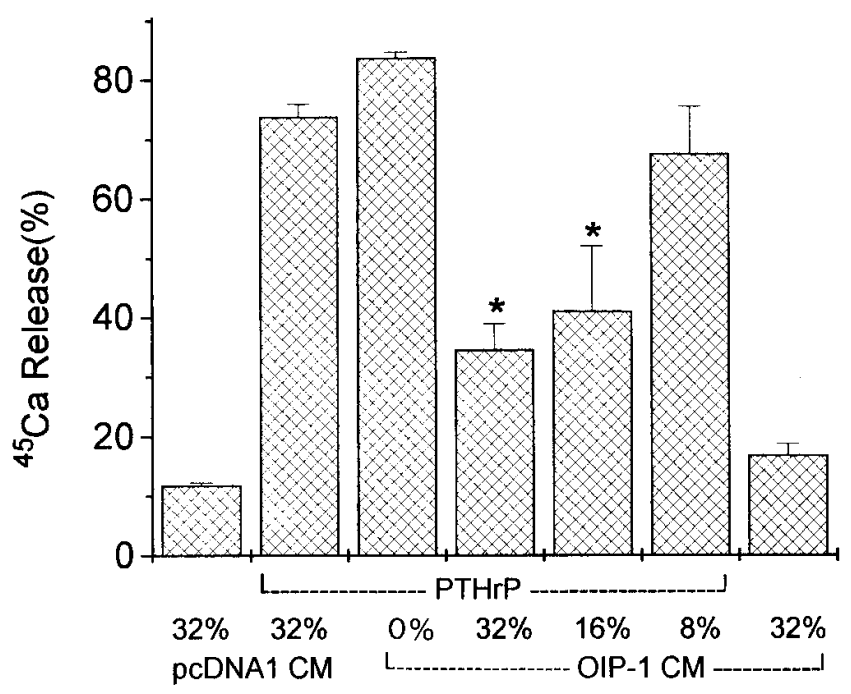

Figure 2. The effects of conditioned media from 293 cells transfected with OIP-1 cDNA on bone resorption in fetal rat long bone cultures. ${ }^{45} \mathrm{Ca}$-labeled fetal rat long bones stimulated with PTHrP $(20 \mathrm{ng} / \mathrm{ml})$ or media (no PTHrP) were treated with varying concentrations $(8-32 \%$ $\mathrm{vol} / \mathrm{vol}$ ) of conditioned media (CM) from 293 cells transfected with the OIP-1 cDNA or the empty vector ( $p c D N A 1)$. Results represent the mean of four determinations for a typical experiment. Similar results were seen in three experiments. $* P<0.05$ compared with control value.

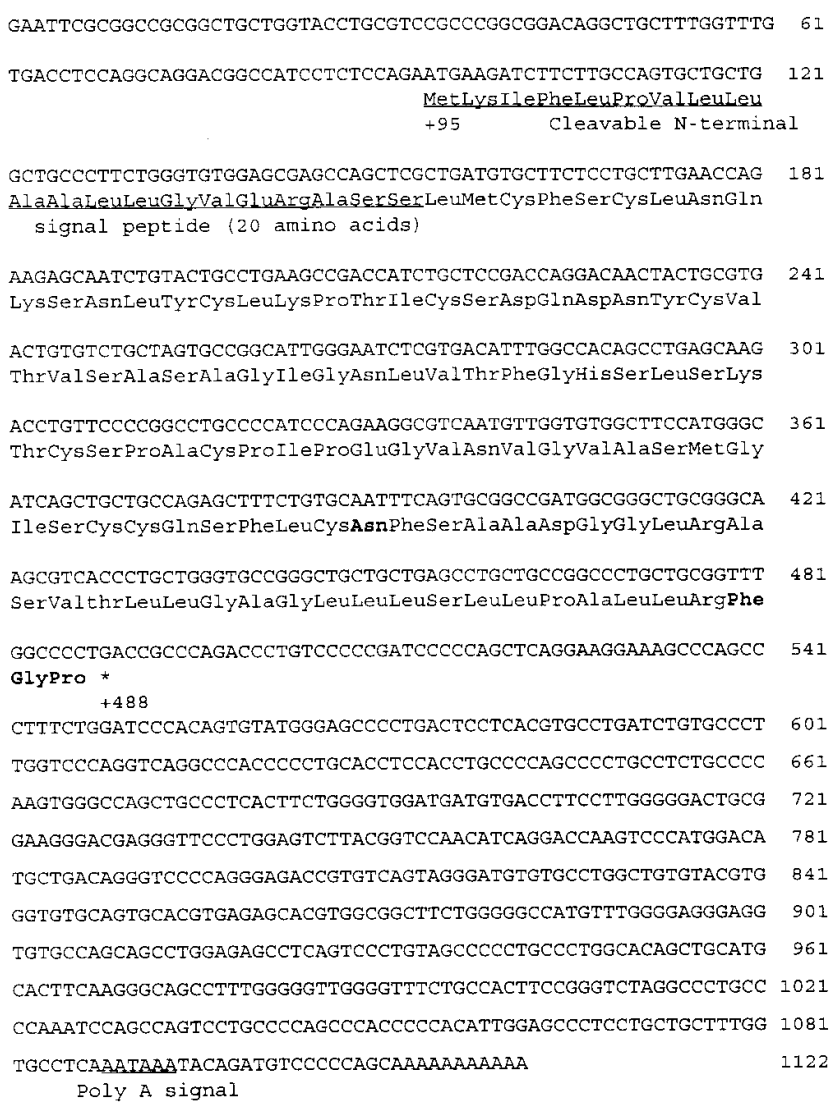

Figure 3. DNA sequence and deduced amino acid sequence of OIP-1. The OIP-1 gene is $1.1 \mathrm{~kb}$ and encodes 131 amino acids. The 20 $\mathrm{NH}_{2}$-terminal amino acids encode a cleavable signal peptide and the $32 \mathrm{COOH}$-terminal amino acids encode a potential GPI-linker peptide. 99 Asn is the potential site for the GPI-linker and also serves as a possible $\mathrm{NH}_{2}$-glycosylation site. The $\mathrm{COOH}$-terminal peptide (PheGlyPro) encodes a cytoplasmic tail.

mRNA expression in human bone marrow and MG-63 osteoblast-like cells on separate Northern hybridization analyses (Fig. $4 \mathrm{~A}$ ). Analysis of human bone marrow cultures by in situ hybridization showed that both MNCs and mononuclear cells expressed OIP-1 mRNA (Fig. $4 \mathrm{~B}$ ).

Expression of recombinant OIP-1 protein. Recombinant OIP-1 protein was expressed in E. coli BL 21 using the PET/ $14 \mathrm{~b}$ system after induction with $1 \mathrm{mM}$ IPTG. The pellet that contained the inclusion bodies was solubilized with $6 \mathrm{M} \mathrm{Gu}$ $\mathrm{HCl}$ and purified with a His-Bind Resin column as described above. Recombinant OIP-1 was eluted with a 50-70 mM imidazole buffer gradient, precipitated by dialysis against water, and solubilized with $10 \mathrm{mM} \mathrm{HCl}$. The recombinant OIP-1 was not soluble in physiologic buffers unless $6 \mathrm{M} \mathrm{GnHCl}$ was added (data not shown). About $200 \mu \mathrm{g}$ of rOIP-1 was purified from 1 liter of $E$. coli culture with more than $95 \%$ purity.

Effect of recombinant E. coli-derived OIP-1 on TRAP(+) $M N C$ formation and bone resorption in fetal rat bone organ cultures. We also tested the effects of recombinant E. coliderived OIP-1 on osteoclast-like MNC formation in mouse and human bone marrow cultures to determine if an OIP-1 protein, which still contained the putative $\mathrm{COOH}$-terminal GPI-linker peptide and lacked the GPI-linker and was not gly- 


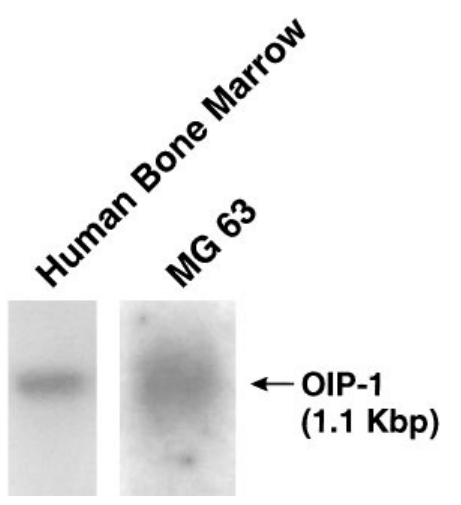

B

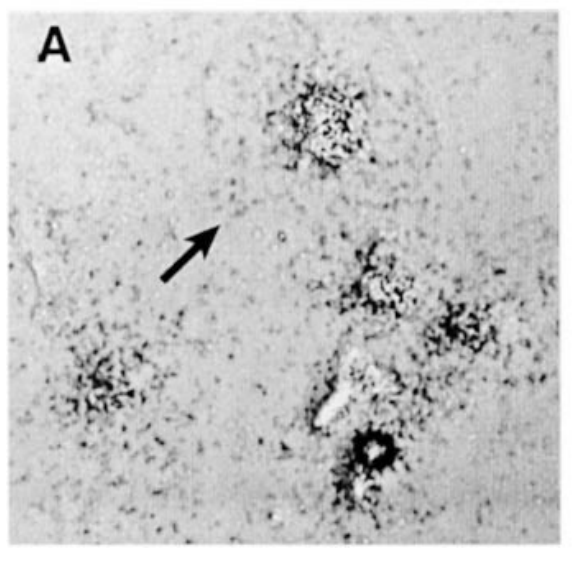

B

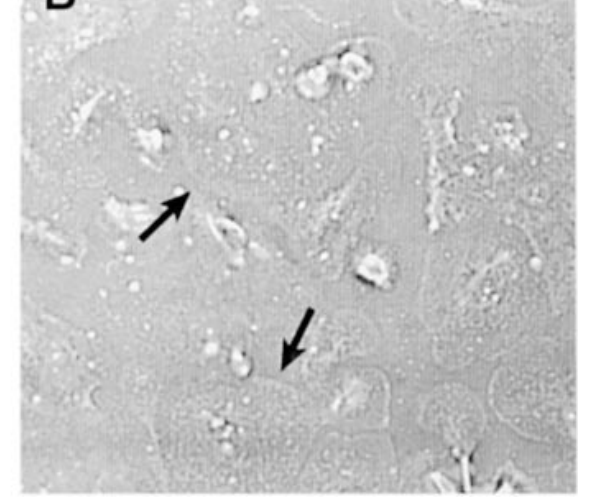

Figure 4. (A) Tissue distribution of OIP-1. A MTN blot was hybridized with a ${ }^{32} \mathrm{P}-$ labeled OIP-1-specific probe generated with random label kit and processed as described in Methods. The highest levels of OIP-1 mRNA expression were present in liver. OIP-1 mRNA was also detected in the human MG-63 osteoblast cell line and human bone marrow. $(B)$ Cellular localization of OIP-1 mRNA in human marrow cultures. Human marrow cultures were treated with $1,25(\mathrm{OH})_{2} \mathrm{D}_{3}$ for $3 \mathrm{wk}$ and then processed for in situ hybridization using sense $(\operatorname{panel} B)$ and antisense $(\operatorname{panel} A)$ probes for OIP-1 mRNA. Both mononuclear cells and MNCs expressed OIP-1 mRNA. cosylated, was biologically active. Surprisingly, in the mouse bone marrow cultures stimulated with PTHrP, recombinant OIP-1 decreased TRAP $(+)$ MNC formation $\sim 60 \%$ at a concentration of $1 \mathrm{ng} / \mathrm{ml}$. Recombinant OIP-1 also inhibited TRAP $(+)$ MNC formation in the presence of $1,25(\mathrm{OH})_{2} \mathrm{D}_{3}$ in a dose-dependent fashion at concentrations of $0.05-5 \mathrm{ng} / \mathrm{ml}$ (Fig. $5 \mathrm{~A}$ ). In human bone marrow cultures, recombinant OIP-1 also decreased 23c6(+) MNC formation induced by $10^{-9} \mathrm{M}$ $1,25(\mathrm{OH})_{2} \mathrm{D}_{3} \sim 60 \%$ at the concentration of $1 \mathrm{ng} / \mathrm{ml}$ (Fig. $5 \mathrm{~B}$ ) and inhibited MNC formation in murine and human marrow cultures treated with PTHrP $\sim 60 \%$ (data not shown). Recombinant OIP-1 was added to mouse bone marrow cultures at different time points, and the osteoclast formation was measured. As shown in Fig. 6, addition of OIP-1 for only the first $2 \mathrm{~d}$ of the cultures significantly inhibited osteoclast formation. Addition of OIP-1 after the first $2 \mathrm{~d}$ of the cultures did not inhibit osteoclast formation. Recombinant OIP-1 also inhibited ${ }^{45} \mathrm{Ca}$ release from ${ }^{45} \mathrm{Ca}$-labeled fetal rat long bones stimulated with $10^{-9} \mathrm{M} 1,25(\mathrm{OH})_{2} \mathrm{D}_{3} \sim 50 \%$ at $10 \mathrm{ng} / \mathrm{ml}$ compared with the vehicle control assay, and inhibited ${ }^{45} \mathrm{Ca}$ release stimulated by PTHrP (20 ng/ml) in a dose-dependent manner (Fig. 7).

Analysis of the intracellular and extracellular forms of OIP-1. We tested conditioned media from 293 cells and CHO cells that had been transiently transfected with the OIP-1 cDNA, as well as conditioned media from human bone marrow cultures that had formed osteoclast-like cells, for the presence of OIP-1 by Western blot analysis using antisera raised in rabbits against E. coli-derived recombinant OIP-1. As shown in Fig. $8 A$, the OIP-1 in these conditioned media was slightly larger (16 kD) than rOIP-1. This difference in the electrophoretic mobility of the mammalian OIP-1 most likely results from addition of the
GPI anchor, which is added as a post-translational modification to OIP-1 in eukaryotic but not prokaryotic cells. In human bone marrow culture-conditioned media, the higher molecular weight band that was detected could be due to cell-specific post-translational modifications such as glycosylation. Since GPI-linked proteins have a cleavable $\mathrm{COOH}$-terminal peptide and can be shed from the cell surface in membrane-bound vesicles or the GPI anchor cleaved by PLC, we analyzed the intracellular and extracellular forms of OIP-1. Cell lysates and ultracentrifugation fractions of conditioned media from 293 cells transiently transfected with the OIP-1 cDNA were subjected to immunoblot analysis. The cell lysates contained the predicted $14 \mathrm{kD}$ intracellular form of OIP-1 under reducing and nonreducing conditions, and was similar in size to the recombinant OIP-1 expressed in E. coli. No OIP-1 was detected in the ultracentrifugation supernatants. A band migrating with an apparent molecular weight of $16 \mathrm{kD}$ was detected under reducing conditions with DTT and $\beta$-mercaptoethanol treatment in the ultracentrifugation pellet. PI-PLC treatment of the OIP-1 present in the pellet decreased the apparent molecular weight of OIP-1 to $14 \mathrm{kD}$, and PNGase F (New England Biolabs) treatment further decreased the apparent molecular weight of OIP-1 to $11 \mathrm{kD}$ (Fig. 8 B).

Effect of recombinant OIP-1 on other cell types. Cells of different lineages other than osteoclasts were treated with rOIP-1 to assess the inhibitory potential of OIP-1 for other cell types. Cell lines were treated with rOIP-1 $(5 \mathrm{ng} / \mathrm{ml})$ for $62 \mathrm{~h}$, and the number of viable cells was determined. The growth of all of these cell lines was not inhibited by treatment with recombinant OIP-1 compared with the control vehicle or media treatment (Table I). 
Table I. Effects of OIP-1 on the Growth of Different Cell Types

\begin{tabular}{lllll}
\hline Cell line & \multicolumn{1}{c}{ Cell type } & Control & $10 \mathrm{mM} \mathrm{HCl}$ & OIP-1 (5 ng/ml) \\
\hline U937 & Human monocytic & $6.1 \times 10^{5}$ & $5.9 \times 10^{5}$ & $6.4 \times 10^{5}$ \\
KMT-2 & Human hematopoietic & $1.9 \times 10^{5}$ & $1.4 \times 10^{5}$ & $1.8 \times 10^{5}$ \\
ANB-IL-6 & Human myeloma & $1.4 \times 10^{5}$ & $1.2 \times 10^{5}$ & $3.6 \times 10^{5}$ \\
ARH-77 & Human myeloma & $2.5 \times 10^{5}$ & $3.4 \times 10^{5}$ & $3.1 \times 10^{5}$ \\
FDCP-1 & Mouse hematopoietic & $9.4 \times 10^{5}$ & $7.8 \times 10^{5}$ & $8.2 \times 10^{5}$ \\
PSV-10 & Human marrow stroma & $2.1 \times 10^{5}$ & $2.5 \times 10^{5}$ & $3.8 \times 10^{5}$ \\
ST-2 & Mouse marrow stroma & $3.1 \times 10^{5}$ & $2.6 \times 10^{5}$ & $4.3 \times 10^{5}$ \\
SAKA & Human marrow stroma & $3.6 \times 10^{4}$ & $5.2 \times 10^{4}$ & $3.4 \times 10^{5}$ \\
HELA & Human cervical epithelium & $2.9 \times 10^{5}$ & $1.5 \times 10^{5}$ & \\
\hline
\end{tabular}

Cells were plated at $1 \times 10^{5} / \mathrm{ml}$ at the initiation of culture in the presence or absence of $5 \mathrm{ng} / \mathrm{ml} \mathrm{rOIP-1}$ or an equivalent amount of vehicle or culture media. Results represent mean of triplicate cultures for a typical experiment. Results do not differ significantly for each treatment group for a particular cell line. A similar pattern of results was seen in two independent experiments.
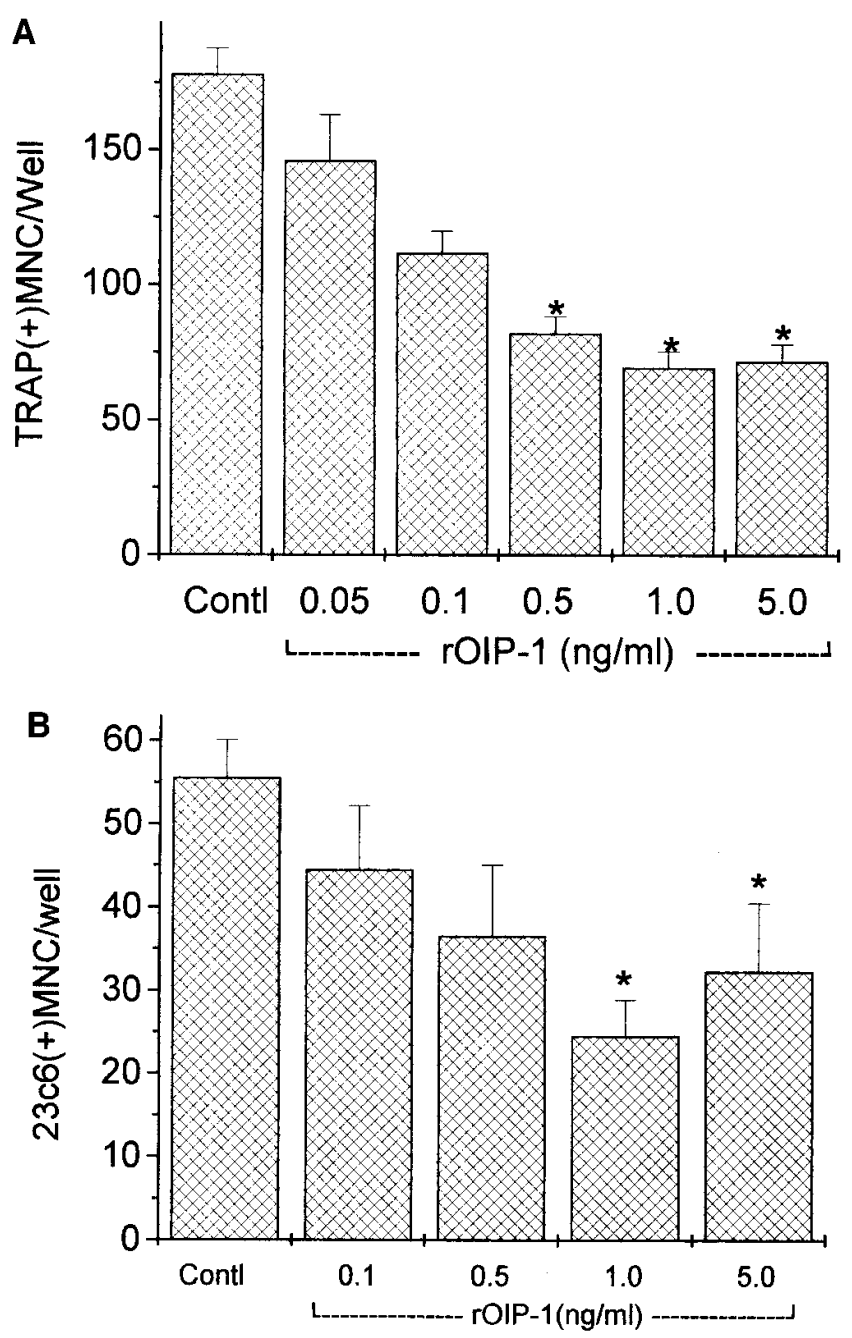

Figure 5. The effects of recombinant OIP-1 expressed in E. coli on mouse and human bone marrow osteoclast-like MNC formation. Varying concentrations of rOIP-1 $(0.05-5 \mathrm{ng} / \mathrm{ml})$ were added to normal mouse $(A)$ or human $(B)$ bone marrow cultures stimulated with $10^{-9} \mathrm{M} 1,25(\mathrm{OH})_{2} \mathrm{D}_{3}$. Control vehicle contained $2 \mu \mathrm{l}$ of $10 \mathrm{mM} \mathrm{HCl}$. Results are reported as the number of TRAP $(+) \mathrm{MNCs} /$ well $(A)$ and $23 \mathrm{c} 6(+) \mathrm{MNCs} /$ well $(B)$, and represent the mean \pm SEM for four determinations. A similar pattern of results was found in four independent experiments. $* P<0.05$ compared with the control value.

\section{Discussion}

We have used an expression cloning approach to identify a novel inhibitor of human and murine osteoclast formation and bone resorption, OIP-1. OIP-1 inhibited osteoclast-like cell formation in human and murine marrow cultures in a dosedependent fashion and inhibited osteoclastic bone resorption in fetal rat long bone cultures. Furthermore, OIP-1 only inhibited osteoclast formation when added at the proliferative stage (days 1-3) of murine marrow cultures (18), suggesting that OIP-1 blocks osteoclast precursor proliferation. The inhibitory effects of OIP-1 appear to be selective to cells in the osteoclast lineage, and not due to nonselective cytotoxicity, since the growth of cells from other lineages was not inhibited by OIP-1 at concentrations that markedly inhibit osteoclast-like cell formation. The relative potency of OIP-1 in terms of its capacity

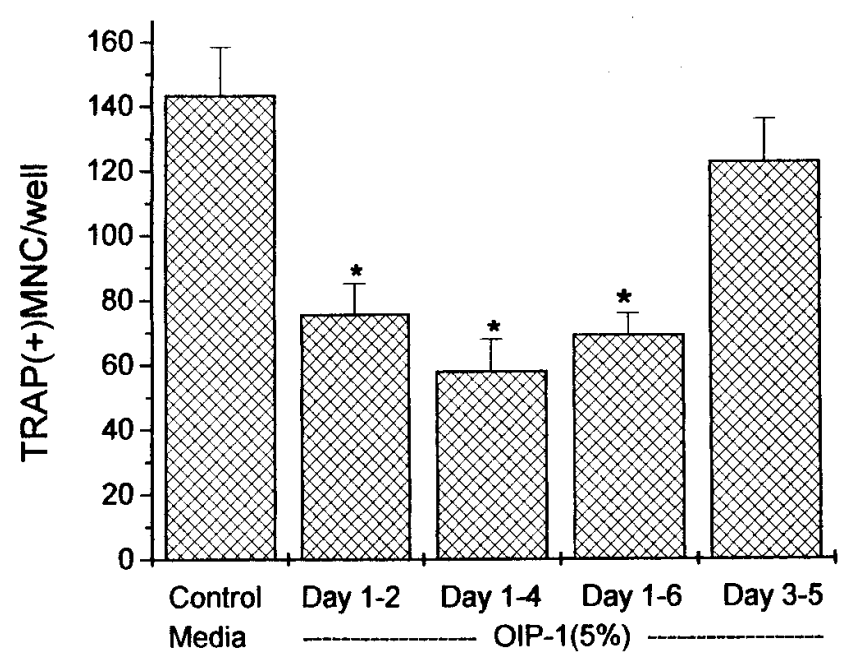

Figure 6. Time course studies of the effects of rOIP-1 on osteoclast formation in murine marrow culture. OIP-1-conditioned media was added to cultures treated with $10^{-9} \mathrm{M} 1,25(\mathrm{OH})_{2} \mathrm{D}_{3}$ for the days specified. Addition of OIP- 1 after the first $2 \mathrm{~d}$ of cultures did not inhibit osteoclast-like cell formation. Results are reported as the number of TRAP $(+) \mathrm{MNCs} /$ well and represent the mean \pm SEM for four determinations. A similar pattern of results was found in four independent experiments. $* P<0.05$ compared with the control value. 


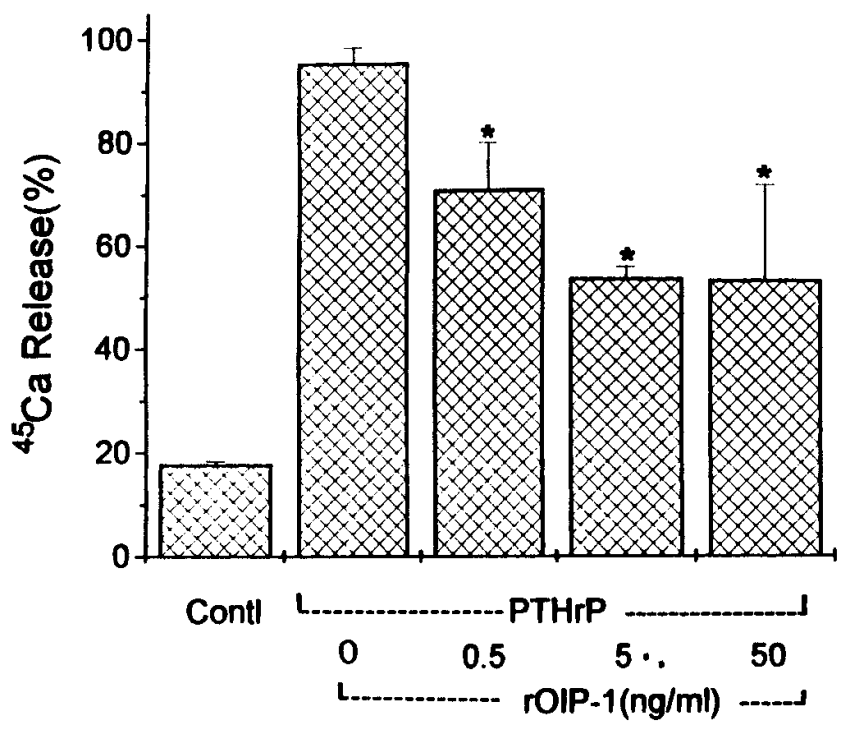

Figure 7. The inhibitory effects of rOIP-1 on bone resorption in fetal rat long bone cultures. ${ }^{45} \mathrm{Ca}$-labeled fetal rat long bones stimulated with PTHrP $(20 \mathrm{ng} / \mathrm{ml})$ or media (control) were treated with varying concentrations of rOIP-1 $(0.5-50 \mathrm{ng} / \mathrm{ml})$. Results represent the mean \pm SEM for a typical experiment. A similar pattern of results was found in three independent experiments.

to inhibit osteoclast formation and bone resorption in fetal rat bone organ cultures is similar to that reported for calcitonin cultures and TGF- $\beta$, although TGF- $\beta$ was a more potent inhibitor of human osteoclast-like cell formation $(6,19)$.

OIP-1 mRNA was expressed by a wide variety of tissues and was also expressed by osteoclasts and MG-63 cells. MG-63 cells are very similar to primary human osteoblasts (20), suggesting that human osteoblasts may also express OIP-1. These data further suggest that OIP-1 may act as both an autocrine and paracrine regulator of osteoclast activity.

Sequence analysis of OIP-1 predicted that it was a GPIlinked peptide with cleavable $\mathrm{COOH}$-terminal and $\mathrm{NH}_{2}$-terminal signal peptides and N-glycosylation sites. GPI-linked proteins have the GPI anchors attached at the cell surface, and the $\mathrm{COOH}$-terminal peptide cleaved at the time of the attachment of the GPI anchor (21). Immunoblot analysis of the released form of OIP-1 supported these structural features. PLC treatment of OIP-1 suggested that there was a $2 \mathrm{kD}$ GPI linker present on the secreted form of OIP-1. PNGase treatment of OIP-1 resulted in a further decrease in the apparent molecular weight to a size that was consistent with that predicted for the protein backbone with the $\mathrm{COOH}$-terminal peptide cleaved off. However, none of these structural features, cleavage of the $\mathrm{COOH}$-terminal peptide, the GPI anchor, or even the potential glycosylation sites appear to be required for the inhibitory effects of OIP-1 on osteoclast-like cell formation. This is suggested by our findings that the recombinant $E$. coli-derived OIP-1, which we constructed for production of a polyclonal antibody to OIP-1, inhibited osteoclast-like cell formation in both human and murine systems in a dose-dependent fashion. The recombinant E. coli-derived OIP-1 we produced contains the entire open reading frame, lacks the GPI anchor, is not glycosylated, and still contains the COOH-terminal peptide. These data demonstrate that post-translational modification of the protein is not required for the inhibitory effects of OIP-1 on osteoclast formation.

Our studies demonstrate that OIP-1 is released from the cell surface in a membrane-bound form. Ultracentrifugation of conditioned media from 293 cells transfected with the OIP-1 cDNA, followed by Western blotting of the supernatants and resuspended pellet with the OIP-1 polyclonal antibody, showed that OIP-1 was only detectable in the pellet. Englund et al. (22) reported that GPI-anchored molecules can be cleaved from cells by certain phosphatidylinositol-specific phospholipases to produce hydrophilic derivatives. Similarly, Rooney et al. (23) reported that GPI-anchored proteins, for example CD59, CD55, Cdw52, and CD45, are present in a membrane-bound form (vesicle form) as well as a membranefree form in seminal plasma.

Analysis of the nucleotide and derived amino acid sequences for OIP-1 show that it is identical to the recently reported hSca/RIG-E gene. This gene is a member of the human Ly6 family of proteins, with homology to the mouse TSA-1 gene and other members of the Ly6 family, as well as several cobra venom neurotoxins (14). This homology is evident in the conservation of cysteine residues in the molecules. However, there is no significant homology with the recently discovered antiresorptive agent, osteoprotegerin (24).

The Ly6 gene family represents a class of molecules that may have particular importance in osteoclast-osteoblast interactions. Horowitz and coworkers (25) have shown that primary osteoblasts and MC3T3 cells constitutively express both Ly6A and Ly6C antigens, although Ly6C was less abundant. Previously, only one human Ly6 gene family member was known, E48, which is identical to the mouse THB gene, a GPIanchored molecule that is apparently involved in keratinocytes cell-to-cell adhesion (26).

The mechanism responsible for OIP-1's inhibition of osteoclast activity is currently unknown. Recently, Solomon et al. (27) reported that GPI-anchored proteins on the surface of lymphocytes act as signal transduction proteins. Many of these proteins can stimulate lymphocyte proliferation, lymphokine production, calcium mobilization, and tyrosine phosphorylation. Stefanova et al. (28) reported that GPI-anchored proteins expressed on lymphocytes coimmunoprecipitate with the src family member tyrosine kinases lck, fyn, fgr, lyn, and hck. In addition, a number of unidentified kinase substrates are also coimmunoprecipitated with GPI-anchored proteins. However, it is not known how these molecules, which lack an intracellular domain, can activate the intracellular signal pathway. $\mathrm{Hu}-$ man GPI-linked molecules CD59, CD55, CD48, CD24, and CD14 as well as mouse Thy- 1 and Ly6 have key regulatory functions and induce signal transduction through tyrosine kinases. These data suggest that human OIP-1 may inhibit osteoclast activity through activation of the tyrosine kinase signal transduction pathway.

In summary, we have identified a novel inhibitor of osteoclast activity, OIP-1, that is released as a membrane-bound GPI-linked protein. OIP-I is a member of the human Ly6 family of proteins, and our findings represent the first description of a biologic activity for this class of human proteins. Our studies suggest that OIP-1 could act as either an autocrine regulator of osteoclasts or as a paracine factor involved in osteoblast-osteoclast interactions in the marrow despite its widespread tissue distribution. These data further suggest that the identification of the mechanism of action for the inhibitory 

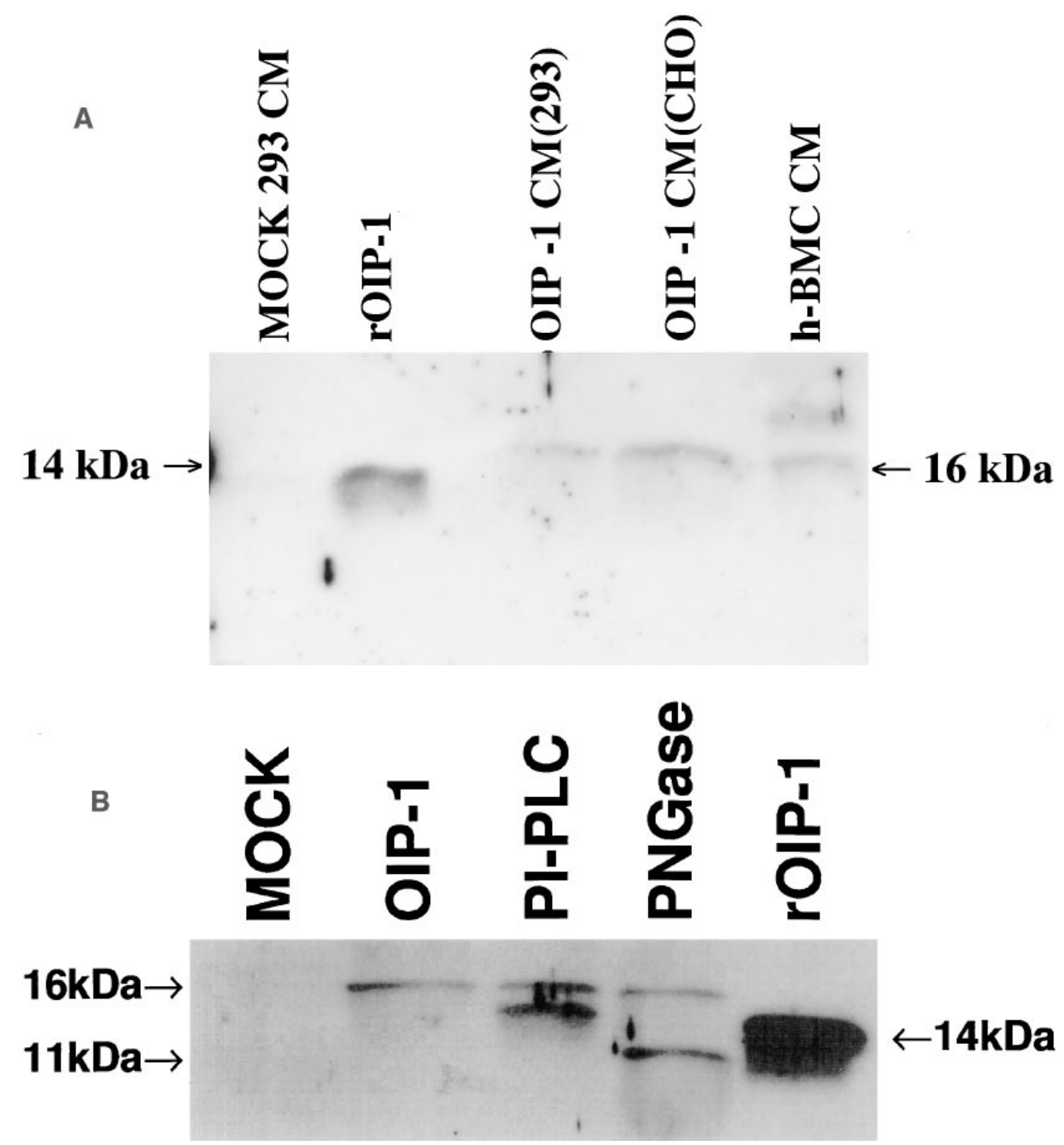

Figure 8. Analysis of the intracellular and extracellular forms of OIP-1. (A) Immunoblot analysis of OIP-1 secreted into media conditioned by 293 cells or $\mathrm{CHO}$ cells transiently transfected with the OIP-1 cDNA or conditioned media from normal human marrow cultures. A $16 \mathrm{kD}$ band was detected in all these conditioned media. rOIP-1 produced in $E$. coli gave a $14 \mathrm{kD}$ band, reflecting the absence of the GPI anchor in the prokaryotic OIP-1. (B) Exported forms of OIP-1 produced by 293 cells. Ultracentrifugation pellet of conditioned media from 293 cells transfected with OIP-1 cDNA was prepared as described in Methods and electrophoresed by PAGE electrophoresis, followed by Western blotting with an OIP-1 polyclonal antisera. A $16 \mathrm{kD}$ band was detected in the ultracentrifugation pellet, and PNGase F treatment showed an $11 \mathrm{kD}$ band consistent with cleavage of the 32 amino acid $\mathrm{COOH}$-terminal peptide from the conditioned media. PLC treatment of solubilized pellet from conditioned media decreased the apparent molecular weight of the OIP-1 to $14 \mathrm{kD}$ consistent with the loss of a 2-3 kD GPI-anchor. Recombinant full-length $E$. coli-derived OIP-1 $(50 \mathrm{ng})$ was used as a control.

effects of OIP-1 on osteoclast activity may provide important insights into the control of the normal bone remodeling process.

\section{Acknowledgments}

The authors thank Judy Anderson for technical assistance, Dr. John Chirgwin for his helpful discussions, Dr. Steve Harris for help with Northern blot analysis of osteoblast expression of OIP-1 mRNA, and Bibi Cates for expert preparation of the manuscript.

This work was supported by Research Funds from the Veterans Administration and National Institutes of Health NIAMS grants AG13625 and AR41336 and National Institute of Arthritis, Diabetes, and Digestive and Kidney Diseases grant AM35188.

\section{References}

1. Roodman, G.D. 1996. Advances in bone biology: the osteoclast. Endocr. Rev. 17:308-332.

2. Takahashi, S., S.V. Reddy, J.M. Chirgwin, R.D. Devlin, C. Haipek, J. Anderson, and G.D. Roodman. 1994. Cloning and identification of Annexin II as an autocrine/paracrine factor that increases osteoclast formation and bone resorption. J. Biol. Chem. 269:28696-28701.

3. Reddy, S.V., R.D. Devlin, R. Nishimura, S.J. Choi, T. Yoneda, and G.D. Roodman. 1997. Isolation and characterization of a cDNA clone encoding a novel peptide (OSF) that enhances osteoclast formation and bone resorption. $J$. Cell. Physiol. In press.

4. Oursler, M.J. 1994. Osteoclast synthesis, secretion and activation of latent transforming growth factor beta. J. Bone Miner. Res. 9:443-452.

5. Pfeilschifter, J., and G.R. Mundy. 1987. Modulation of type beta transforming growth factor activity in bone cultures by osteotropic hormones. Proc. Natl. Acad. Sci. USA. 84:2024-2028.

6. Chenu, C., J. Pfeilschifter, G.R. Mundy, and G.D. Roodman. 1988 Transforming growth factor beta inhibits formation of osteoclast-like cells in long-term human bone marrow cultures. Proc. Natl. Acad. Sci. USA. 85:56835687.

7. Nosjean, O., A. Briolay, and B. Roux. 1997. Mammalian GPI proteins: sorting, membrane residence and functions. Biochem. Biophys. Acta. 1331:153186.

8. Takahashi, N., H. Yamana, S. Yoshiki, G.D. Roodman, G.R. Mundy, S.J. Jones, A. Boyde, and T. Suda. 1987. Osteoclast-like cell formation and its regulation by osteotropic hormones in mouse bone marrow cultures. Endocrinology. 122:1373-1382.

9. MacDonald, B.R., N. Takahashi, L.M. McManus, J. Holahan, G.R. Mundy, and G.D. Roodman. 1987. Formation of multinucleated cells that respond to osteotropic hormones in long term human bone marrow cultures. Endocrinology. 120:2326-2333.

10. Raisz, L.G., and I. Niemann. 1969. Effect of phosphate, calcium and magnesium on bone resorption and hormonal responses in tissue culture. Endocrinology. 85:446-452.

11. Reddy, S.V., S. Takahashi, M. Dallas, R.E. Williams, L. Neckers, and G.D. Roodman. 1994. Interleukin-6 antisense deoxyoligonucleotides inhibit bone resorption by giant cells from human giant cell tumors of bone. J. Bone Miner. Res. 9:753-757.

12. Reddy, S.V., F.R. Singer, L. Mallette, and G.D. Roodman. 1996. Detection of measles virus nucleocapsid transcripts in circulating blood cells from pa- 
tients with Paget disease. J. Bone Miner. Res. 11:1602-1607.

13. Cohen, E.H., and B.E. Landgraf. 1995. 9804 Gene and Methods of Use Thereof. U.S. Patent 5,468,612, U.S. Government, Washington, D.C.

14. Capone, M.C., D.M. Gorman, E.P. Ching, and A. Zlotnik. 1996. Identification through bioinformatics of cDNAs encoding human thymic shared Ag-1/stem cell Ag-2. J. Immunol. 157:969-973.

15. Mao, M., M. Yu, J.H. Tong, J. Ye, J. Zhu, Q.H. Hung, G. Fu, L. Yu, S.Y. Zhao, S. Waxman, et al. 1996. RIG-E, a human homolog of the murine Ly-6 family, is induced by retinoic acid during the differentiation of acute promyelocytic leukemia cell. Proc. Natl. Acad. Sci. USA. 93:5910-5914

16. Davies, A., D.L. Simmons, G. Hale, R.A. Harrison, H. Tighe, P.J. Lachmann, and H. Waldmann. 1989. CD59, an Ly-6 like protein expressed in human lymphoid cells, regulates the action of the complement membrane attack complex on homologous cells. J. Exp. Med. 170:637-654.

17. Classon, B.J., and L. Converdale. 1994. Mouse stem cell antigen Sca-2 is a member of the Ly-6 family of cell surface proteins. Proc. Natl. Acad. Sci. USA. 91:5296-5300.

18. Biskobing, D.M., X. Fan, and J. Rubin. 1995. Characterization of MCSF-induced proliferation and subsequent osteoclast formation in murine marrow culture. J. Bone Miner. Res. 10:1025-1032.

19. Pfeilschifter, J., S.M. Seyedin, and G.R. Mundy. 1988. Transforming growth factor beta inhibits bone resorption in fetal rat long bone cultures. $J$. Clin. Invest. 82:680-685.

20. Bonewald, L.F., M.B. Kester, Z. Schwartz, L.D. Swain, A. Khare, T.L. Johnson, R.J. Leach, and B.D. Boyan. 1992. Effects of combining transforming growth factor $\beta$ and 1,25-dihydroxyvitamin $\mathrm{D}_{3}$ on differentiation of a human os- teosarcoma (MG-63). J. Biol. Chem. 267:8943-8949.

21. Medof, M.E., S. Nagarajan, and M.L. Tykocinski. 1996. Cell-surface engineering with GPI-anchored proteins. FASEB J. 10:574-586.

22. Englund, P.T. 1993. The structure and biosynthesis of glycosyl phosphatidyl inositol protein anchors. Annu. Rev. Biochem. 62:121-138.

23. Rooney, I.A., J.E. Heuser, and J.P. Atkinson. 1996. GPI-anchored complement regulatory proteins in seminal plasma. J. Clin. Invest. 97:1675-1686.

24. Simonet, W.S., D.L. Lacey, C.R. Dunstan, M. Kelley, M-S. Chang, R.

Luthy, H.Q. Nguyen, S. Wooden, L. Bennett, and T. Boone. 1997. Osteoprotegerin: a novel secreted protein involved in the regulation of bone density. Cell. 89:309-319.

25. Horowitz, M.C., A. Fields, D Demeo, H.Y. Oian, A.L.M. Bothwell, and E. Trepman. 1994. Expression and regulation of Ly6 differentiation antigens by murine osteoblasts. Endocrinology. 135:1032-1043.

26. Brackenhoff, R.H., M. Gerretsen, E.M.C. Knippels, M.V. Dijk, H.V. Essen, D.O. Weghuis, R.J. Sinke, G.B. Snow, and G.A.M.S. Dongen. 1995. The human E48 antigen, highly homologous to the murine Ly6 antigen ThB, is a GPI-anchored molecule apparently involved in keratinocyte cell-cell adhesion. J. Cell. Biol. 129:1677-1689.

27. Solomon, K.R., C.E. Rudd, and R.W. Finberg. 1996. The association between glycosylphosphatidylinositol-anchored proteins and heterotrimeric protein $\alpha$ subunits in lymphocytes. Proc. Natl. Acad. Sci. USA. 93:6053-6058.

28. Stefanova, I., V. Horejsi, I.J. Ansotegui, W. Knapp, and H. Stockinger. 1991. GPI-anchored cell-surface molecules complexed to protein tyrosine kinases. Science. 254:1016-1019. 